\title{
A PROTEÇÃO DOS RECURSOS NATURAIS DA RESERVA BIOLÓGI- CA SANTA ISABEL: O PAPEL DAS POPULAÇÕES LOCAIS
}

\author{
Edilaine Andrade Melo ${ }^{1}$ \\ Ana Bárbara de Andrade ${ }^{2}$ \\ Marlucia Cruz de Santana ${ }^{3}$
}

\section{Resumo}

A Reserva Biológica (REBIO) é caracterizada como uma área de proteção integral que tem como objetivo a preservação integral da biota, sem interferência humana direta ou modificações ambientais, excetuando-se as medidas de recuperação de seus ecossistemas alterados e as ações de manejo necessárias para recuperar e preservar o equilíbrio natural. A Reserva Biológica Santa Isabel é uma das regiões de Sergipe que congrega uma área considerável de Restinga. Os conflitos que permeiam esses ecossistemas litorâneos configuram uma série de impactos socioambientais que apontam para perda dos recursos biológicos e culturais. Diante do exposto faz-se necessário analisar a relação da comunidade local com este ambiente na perspectiva de propor alternativas para manejo sustentável da área. A implementação de áreas protegidas tem sido uma das principais ferramentas utilizadas para a proteção da biodiversidade, no entanto, em todo o Brasil é notória a ocorrência de conflitos gerados entre as populações locais e os órgãos gestores a partir da criação das Unidades de conservação. O objetivo deste trabalho foi identificar a atuação das comunidades locais no processo de gestão e manejo da Reserva Biologia Santa Isabel. Os levantamentos de dados em campo foram realizados na região do litoral norte do Estado, no entorno da REBIO, localizada no município de Pirambu, situado na região leste de Sergipe. As reflexões que aludem a presente pesquisa fundamentaram-se no levantamento bibliográfico de dados referentes a temática deste trabalho, na observação sistemática e na realização de entrevistas com residentes de comunidades do entorno da REBIO Santa Isabel. De acordo com as entrevistas desde a criação da Unidade, houve a inclusão de uma pequena parcela da população em ações pontuais relacionados ao Projeto Tamar. Apesar disso, a maioria da população continua excluída, sem participação ativa na construção do plano de manejo, o que revela a carência de atuações por parte dos gestores que envolvam a comunidade local no processo de conservação da área.

Palavras-chave: Unidades de Conservação; Conflitos; Comunidades.

\footnotetext{
Abstract

Biological Reserve (REBIO) is characterized as a strictly protected area that aims to preserve the full biota without direct human interference or environmental changes, except for the recovery measures and their ecosystems changed management actions necessary to restore and preserve the natural balance. The Santa Isabel Biological Reserve is one of the regions of Sergipe that brings a considerable area of Restinga. The

1 Mestranda no curso de Pós-graduação em Desenvolvimento e Meio Ambiente (PRODEMA) da Universidade Federal de Sergipe - Email: edilainemel_bio@yahoo.com.br

2 Mestranda no curso de Pós-graduação em Desenvolvimento e Meio Ambiente (PRODEMA) da Universidade Federal de Sergipe - Email: anyaju@hotmail.com

3 Professora do Departamento de Biologia da Universidade Federal de Sergipe - Email: mar@ufs.br
} 
conflicts that permeate these coastal ecosystems constitute a series of social and environmental impacts that determine a loss of biological and cultural resources. Given the above it is necessary to analyze the relationship of the local community with this environment from the perspective of proposing alternatives for sustainable management of the area. The implementation of protected areas has been one of the main tools used for the protection of biodiversity, however, in Brazil is notorious occurrence of conflicts generated among local populations and management bodies from the creation of conservation units. The aim of this study was to identify the role of local communities in the management process of the Reserve Biology Santa Isabel. The field survey data were conducted in the region's northern coast, in the vicinity of REBIO, located in the municipality of Pirambu, eastern region of Sergipe. The reflections that allude to this research were based on literature data concerning the subject of this work, systematic observation and interviews with residents of the surrounding communities REBIO Santa Isabel. According to the interviews since the creation of the unit, was the inclusion of a small portion of the population in specific actions related to Tamar. Nevertheless, the majority of the population remain excluded without active participation in the construction management plan, which shows the lack of actions by managers involving the local community in the process of conservation area.

Keywords: Conservation Units; Conflicts; Communities. 


\section{Apresentação do tema}

Nos últimos anos a capacidade de alteração da paisagem natural vem sendo incrementada por diversos fatores tais como o crescimento populacional, o aumento do consumismo e os avanços tecnológicos (MORSELLO, 2008). Nessa circunstância, os impactos causados pela exploração da biodiversidade tem se tornado cada vez mais complexos e em razão dessa intensa degradação discute-se a necessidade de um planejamento que viabilize o uso sustentável dos recursos naturais de modo a colocar em prática os escopos do desenvolvimento sustentável.

As discussões que envolvem as problemáticas ambientais caracterizam-se pelo envolvimento de um conjunto de fatores atuantes com perspectiva interdisciplinar que contemplam as inter-relações entre o meio natural e social. Desse modo, permeada por inúmeras questões que envolvem a degradação ambiental, as práticas sociais têm ganhado cada vez mais espaço para reflexão (JACOBI, 2003).

Uma estratégia empregada para minimizar os impactos negativos contra o ambiente natural é a criação de unidades de conservação que além de proteger áreas naturais também pode possibilitar e determinar práticas sustentáveis nessas áreas agora consideradas protegidas. É preciso ressaltar que a concepção de uma política ambiental nacional em conformidade ao Sistema Nacional de Unidade de Conservação (SNUC) foi um passo importante principalmente para a defesa da qualidade do meio ambiente no país, no entanto, essa medida não tem sido suficiente para proteção e recuperação de ecossistemas extremamente ameaçados e tampouco para os processos de inclusão social das comunidades.

Tendo em vista que as unidades de conservação são áreas de interesse ecológico e social faz-se necessário incluir, na política de gestão dessas áreas, o conhecimento e usos que as populações locais fazem dos recursos ali encontrados, inclusive no entorno dessas unidades. Nessa perspectiva, muitos estudos têm enfatizado a relação entre a manutenção da diversidade biológica e cultural, incluindo as populações como grandes responsáveis pela conservação da biodiversidade ao qual fazem parte e dependem para sobreviver (DIEGUES, 2001).

O enfoque desta pesquisa remete ao estudo da relação do homem com o seu ambiente e a importância da conservação dos recursos tanto para os ecossistemas quanto para a sociedade que dele usufrui. Desse modo, o objetivo deste trabalho foi identificar a atuação das comunidades locais no processo de gestão e manejo da Reserva Biologia Santa Isabel, em Sergipe.

\section{Caracterização da área de estudo}

\section{Reserva Biológica Santa Isabel}


Os levantamentos de dados foram realizados no entorno da Reserva Biológica Santa Isabel(Figura 1), criada através do decreto ${ }^{\circ} 96.999$ de 1988 . Essa unidade deconservação engloba formações de Restinga e de outros ecossistemas costeiros, atualmente ela é gerenciada pelo Instituto Chico Mendes de Biodiversidade e Conservação (ICMBIO).

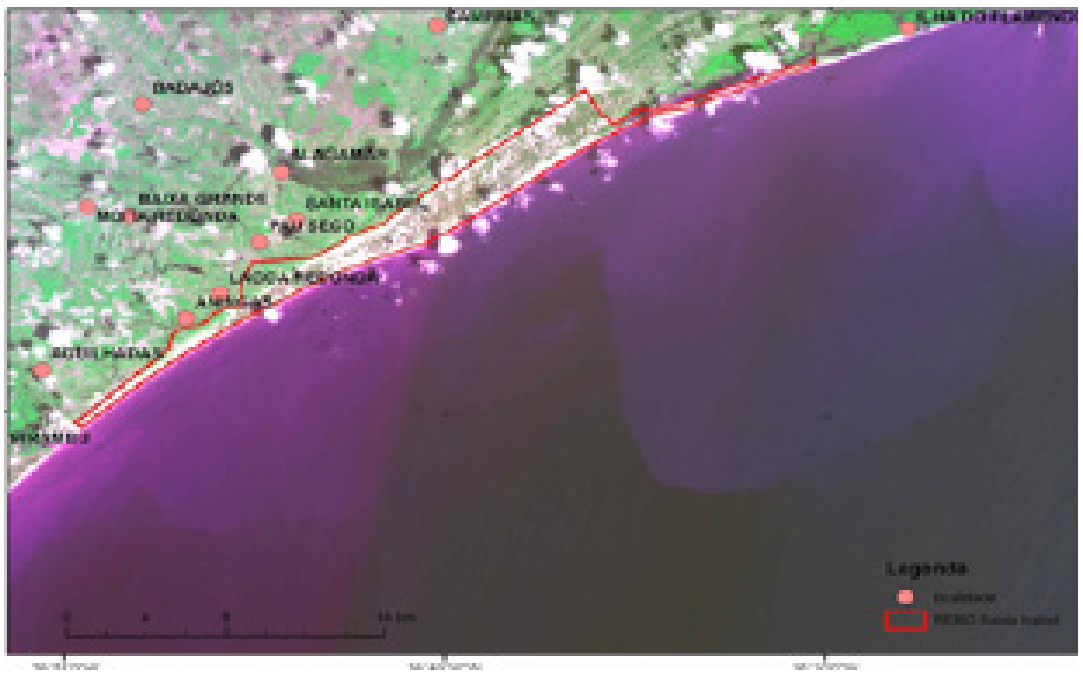

Figura 1: Reserva Biológica Santa Isabel e comunidades adjacentes Fonte: ICMBIO (2011)

A Reserva Biológica (REBIO) é caracterizada como uma área de proteção integral. Ela tem como objetivo a preservação integral da biota e demais atributos naturais existentes em seus limites, sem interferência humana direta ou modificações ambientais, excetuando-se as medidas de recuperação de seus ecossistemas alterados e as ações de manejo necessárias para recuperar e preservar o equilíbrio natural, a diversidade biológica e os processos ecológicos naturais (BRASIL, 2000).

É imprescindível destacar que as Unidades de Conservação, com exceção da Área de Proteção Ambiental e Reserva Particular do Patrimônio Natural, devem possuir uma zona de amortecimento (BRASIL, 2000). A pesquisa aqui delineada tem como área de estudo o entorno da REBIO Santa Isabel e parte do pressuposto que as populações locais presentes nestas áreas devem ser incluídas no processo de tomada de decisão e manutenção dessa Unidade.

De acordo com o Art 2º, inciso XVIII da lei 9985 de 18 de julho de 2000 a zona de amortecimento é definida como o entorno de uma unidade de conservação, onde as atividades humanas também estão sujeitas a normas e restrições específicas, com o intuito de minimizar os impactos negativos sobre a unidade.

O artigo 27 desta mesma lei admite que o Plano de Manejo de uma UC deve abranger não somente a área da unidade de conservação como também a sua zona de amortecimento, incluindo medidas com o fim de promover sua integração à vida econômica e social das comunidades vizinhas. 
mover sua integração à vida econômica e social das comunidades vizinhas.

\section{Procedimentos Metodológicos}

A pesquisa apresenta uma abordagem qualitativa e descritiva. A priori fez-se necessário um levantamento bibliográfico correlato à temática desse trabalho, principalmente as discussões referentes às comunidades locais e Unidades de Conservação. Em seguida foi realizado um reconhecimento preliminar da área de estudo com intuito de observar o ambiente a ser pesquisado e definir as comunidades que seriam estudadas.

Para coleta de dados foram selecionadas quatro comunidades localizadas no entorno da REBIO Santa Isabel (Figura 2): Aguilhadas, Aningas, Lagoa Redonda e Alagamar localizadas nos municípios de Pirambu (SE), que fica na região do leste sergipano.
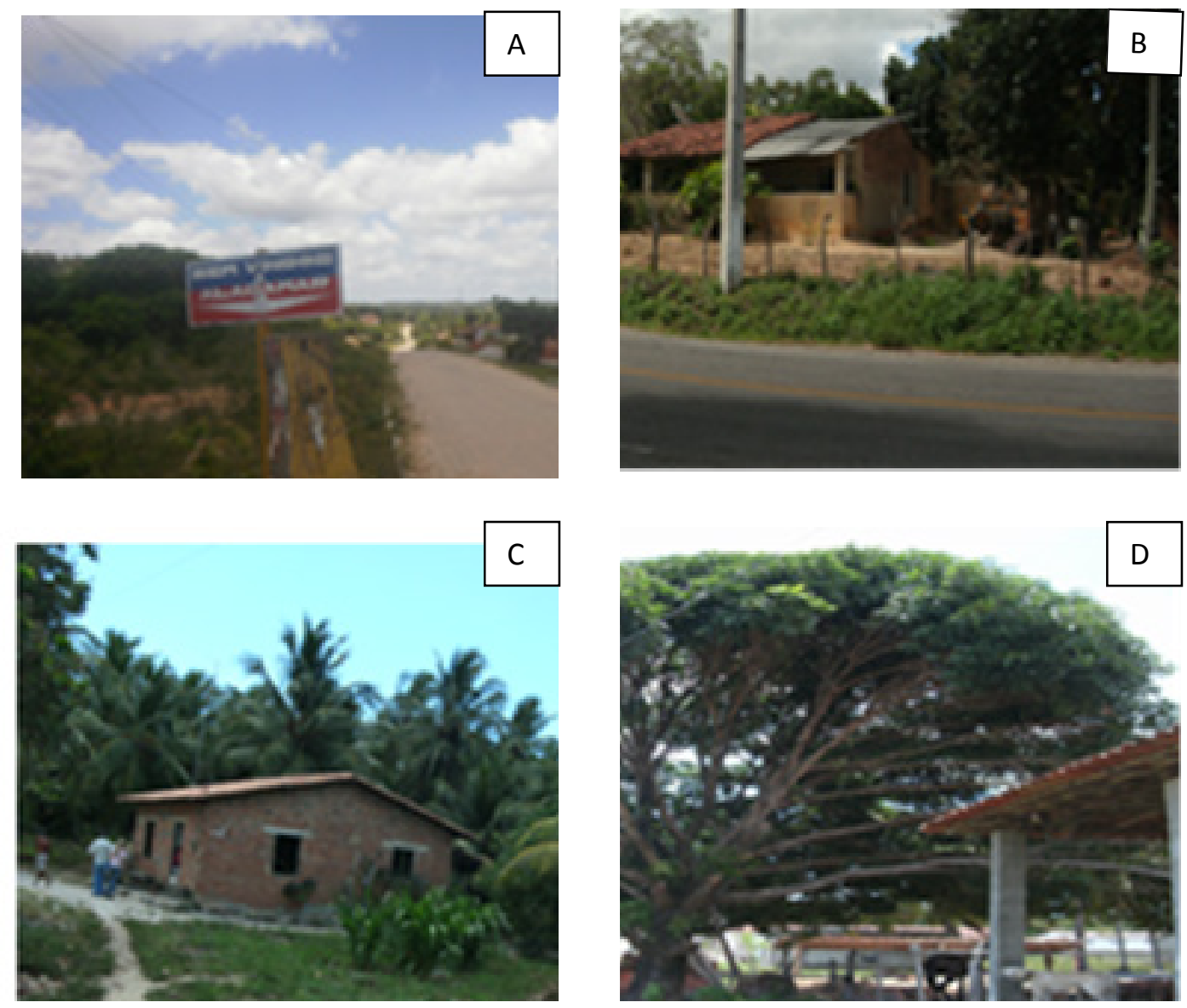

Figura 2. Comunidades rurais estudadas: A) Alagamar, B) Aguilhadas,

C) Aningas e D) Lagoa Redonda, respectivamente.

As comunidades pesquisadas foram determinadas seguindo alguns critérios tais como a proximidade com a área protegida, bem como as características sociais e a relação cotidiana que os residentes mantêm com este ambiente. Sendo assim trata-se de comunidades rurais, que em sua maioria, 
O instrumento metodológico base para acessar as informações com as populações locais foram as entrevistas semiestruturadas aplicadas a alguns membros das comunidades supracitadas. Os respondentes foram determinados de acordo com a faixa etária e tempo de convivência no local, sendo estabelecidos maiores de 18 anos com no mínimo dez anos de residência. Antes de respondê-las os entrevistados assinaram um termo de consentimento livre e esclarecido autorizando a divulgação das informações para a pesquisa. O roteiro de entrevista preparado apresentou questões abertas e fechadas, visto que essa conjuntura apresenta a melhor alternativa para o alcance do objetivo da pesquisa aqui descrita. Se por um lado nas questões abertas os respondentes não se limitam a um conjunto de alternativas, sendo essas menos influenciadoras e capazes trazer comentários e esclarecimentos importantes para análise das demais questões, por outro, as questões fechadas permitem manter o foco e a linearidade, além de facilitar e agilizar o andamento das respostas.

A amostra de entrevistados foi determinada pelo método "Bola de Neve" (Bailey, 1994), a qual tem início a partir do contato com a comunidade local, que por sua vez farão indicações de pessoas chaves, ou seja, pessoas na comunidade que estão inteiradas com as questões locais, que residem ali há algum tempo ou possui conhecimento do ambiente local. Desse modo, quando o primeiro entrevistado foi reconhecido este fez indicação de outros e assim sucessivamente.

Com o intuito de compreender o relacionamento da comunidade em relação ao ambiente local, durante as entrevistas foram levantados os dados gerais do entrevistado bem como questionamentos sobre as atividades sociais e as relações estabelecidas com o ambiente natural e o espaço protegido em seu entorno. Essas relações foram pesquisadas através da afinidade que a comunidade mantém com a reserva, verificando como participa, a maneira como interpretam a função da reserva biológica em estudo, quais as perspectivas locais em relação à vegetação daquele ambiente e as mudanças que ocorreram após a criação de uma Unidade de Conservação no local.

\section{Resultados e discussão}

Durante as visitas à área de estudo, através da observação sistemática do ambiente e das entrevistas com a comunidade, percebeu-se que além do pouco envolvimento da população frente às ações ambientais locais, existem outros fatores desfavoráveis à manutenção da biodiversidade do entorno da REBIO Santa Isabel. Parte desta área apresenta-se descaracterizada, seja pelo uso, ocupação ou por outras atividades antrópicas que degradam e desconfiguram a paisagem local, como podem ser observados nas imagens abaixo (Figura 3). 

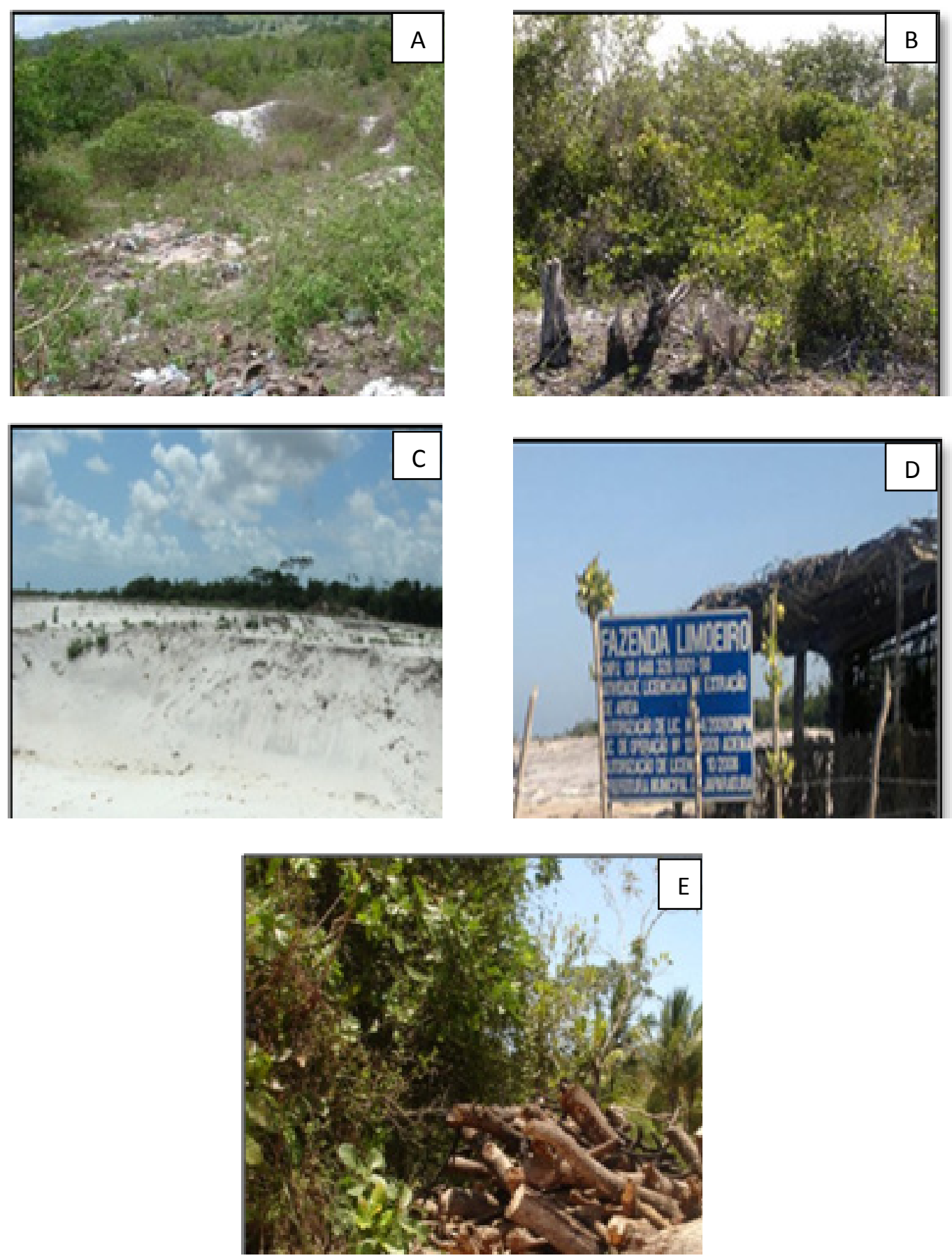

Figura 3 - Evidência de lixo (A), queimadas (B), retirada de areia (C), autorização de exploração do solo em áreas de restinga (D), retirada da vegetação (E). Fotos: Marlucia Santana e Edilaine Melo (2011)

Através das observações foram registrados indícios de degradação ambiental em algumas áreas do entorno da REBIO Santa Isabel, os impactos incluem a prática de queimadas, o despejo indiscriminado de resíduos, a exploração inadequada da vegetação e a extração de areia.

De acordo com Melo et al. (2012), as áreas do entorno da REBIO apresentam uma grande biodiversidade, porém os estudos desenvolvidos 
nesse ecossistema ainda são incipientes. A exploração inadequada do meio pode ocasionar alterações na dinâmica natural deste trazendo, inclusive, perdas irreparáveis para as populações locais que usufruem desse meio.

Os impactos foram visualizados de maneira mais expressiva em locais próximos as comunidades, neste caso, os ambientes naturais foram sujeitos a maior a pressão onde as populações fizeram-se presentes.

Uma das preocupações descritas por Diegues (2001); Cerqueira (2000); Esteves e Lacerda (2000), em relação aos ecossistemas costeiros refere-se à pressão exercida nesses ecossistemas a qual se intensificou gradativamente com o tempo.

De acordo com Esteves e Lacerda (2000), estes ecossistemas têm sofrido um intenso processo de degradação ao longo dos séculos. Com a colonização europeia esses ambientes foram os primeiros a sofrerem com a ação antrópica, principalmente pela sua localização litorânea.

Através das entrevistas, alguns moradores questionaram a deficiência no sistema de coleta de resíduos nos povoados, o que condiciona a população ao despejo inadequado desses, além disso, a maioria atribuiu a culpa deste inadequado descarte a terceiros. Quando questionados sobre a relação com o ambiente natural a sua volta algumas pessoas destacaram que a própria comunidade não está preocupada com a conservação da vegetação local, fator que pode evidenciar o distanciamento da comunidade em relação a esse ambiente, e à necessidade de resgatar a relação de respeito e cognação com a natureza.

Ainda assim, a população que vive no entorno destas áreas afirmaram fazer diferentes usos da vegetação daquele ambiente, foram citados o uso medicinal, ornamental, artesa nal, alimentício, madeireiro e ainda há espécies tradicionalmente muito utilizadas por algumascomunidadescomofontederenda,comoéocasoda Mangabeiraedo Ouricuri.

A Reserva Biológica Santa Isabel ainda não dispõe de plano de manejo. De acordo com as entrevistas desde a criação da Unidade, houve a inclusão de uma pequena parcela da população em atividades relacionadas ao Projeto Tamar, apesar disso nenhum dos entrevistados participou da criação da REBIO e desconhecem as ações de construção do plano de manejo da área.

Segundo Besusan (2006), a implementação de espaços protegidos tem sofrido grandes desafios, sejam em relação ao estabelecimento da unidade e seus impasses, seja pela ausência de um manejo que impeça a pressão excessiva de uso sobre essas áreas.

Quando questionados em relação às mudanças ocorridas após a criação da unidade de conservação, parte da população afirmou que não houve nenhuma modificação onde reside, o que demonstra a carência de atividades que envolvam a participação e integração das comunidades no processo de conservação desses espaços. Outros moradores relataram alguns conflitos e embates com os órgãos ambientais em função da legislação ambiental que regem os espaços protegidos. 
apresentam uma grande biodiversidade, porém os estudos desenvolvidos nesse ecossistema ainda são incipientes. A exploração inadequada do meio pode ocasionar alterações na dinâmica natural deste trazendo, inclusive, perdas irreparáveis para as populações locais que usufruem desse meio.

Para a população, as ações de Educação Ambiental e outras formas de participação, quando existem, ficam restritas aos colégios ou as atividades do Projeto TAMAR e raramente chegam à população dos povoados.

Ainda assim, os entrevistados afirmaram que houve algumas mudanças ocorridas após a criação da UC, principalmente no que se refere às medidas de restrição de uso dos recursos vegetais locais, feita pelos órgãos ambientais.

Os entrevistados relataram a atuação destes órgãos quanto à implantação de regras e às advertências de uso no espaço do entorno da REBIO Santa Isabel, e questionaram a ausência de alternativas que poderiam ser propostas para aliar o uso e conservação dos recursos. Conforme observado nas falas abaixo:

"A gente não pode mais nem pegar um "pé de pau" pra consertar uma cerquinha que eles não deixam" (Moradora A: Povoado Lagoa Redonda) "Ouvir dizer que eles estão se reunindo pra proibir o pessoal de tirar o Ouricuri, mas aí vai viver de quê??" (Moradora C: Povoado Aguilhadas) "Num posso nem tirar uma árvore da minha propriedade que eles não querem, e é da minha terra que era de minha mãe há muitos anos..." (Moradora B: Povoado Aningas)

Estudos relatam que sem o apoio da comunidade local, as ações conservacionistas podem ocasionar efeito oposto aos ideais de conservação dos ecossistemas. O que ocorre quando a criação dos espaços protegidos acontece de forma autoritária, sem a participação da comunidade residente na área (DIEGUES, 2001; BENSUSAN, 2006).

Os fatos relatados alertam para a necessidade de políticas públicas, alternativas e propostas capazes de promover a conservação do ecossistema local sem trazer implicações para a comunidade e o ambiente, minimizando os conflitos socioambientais locais. É preciso ressaltar a necessidade de medidas básicas, como a eficiência de um sistema de coleta de resíduos que impeça o descarte inadequado no meio, e ações de educação ambiental que integre e sensibilize a comunidade quanto à importância do ambiente à sua volta e necessidade de conservá-lo.

\section{Considerações Finais}

A comunidade que reside no entornoda Reserva BiológicaSanta Isabel permanece sem participação ativa no manejo dos recursos ambientais locais, fator este que ocasiona os vários conflitos en contrados na região de estudo que perpassam desde a degradação da comunidadebióticaatéa exclusãodaspopulaçõeshumanasdoprocessodeconservação. 


\section{Referências}

BAILEY, K. D. Methods of social research. 4ed. New York: The free press, 1994. Disponível em: http://www.amazon.com/Methods-Social-Research-Kenneth-Bailey/html.Acesso em: agosto de 2011.

BENSUSAN, Nurit. Conservação da Biodiversidade em Áreas Protegidas. Rio de Janeiro: Editora FGV, 2006.176p.

BRASIL/DIÁRIO OFICIAL DA UNIÃO de $21 / 10 / 1998 . \quad$ Decreto de 20 de outubro de 1988. Cria a Reserva Biológica Santa Isabel. Imprensa Nacional. Brasília, Seção 1. p. 20505, 1988.

BRASIL, Sistema Nacional de Unidades de Conservação - SNUC. Lei Número 9985 de 18 de julho de 2000. Brasília: 2000. Disponível em: http://www.planalto.gov.br/ccivil_03/leis/19985.html

CERQUEIRA, R. Biogeografia das Restingas. In: Ecologia de restingas e lagoas costeiras. ESTEVES, F. A.; LACERDA, L. D. (Eds). Macaé: UPEM/UFRJ, 2000.

DIEGUES, Antônio Carlos. Ecologia humana e planejamento em áreas costeiras. 2 ed. São Paulo: Núcleo de Apoio à Pesquisa sobre as Populações Humanas em Áreas Úmidas Brasileiras, USP, 2001.

ESTEVES, F. A.; LACERDA, L. D. Restinga Brasileira: 15 anos de estudos. In: Ecologia de restingas e lagoas costeiras. UPEM/UFRJ, Macaé, 2000.

JACOBI, P. $\quad$ Educação $\quad$ Ambiental, Cidadania e Sustentabilidade. Cadernos de Pesquisa, n. 118, 2003.

MELO, E.A.; ANDRADE, A. B.; SANTANA, M. C. Conflitos Socioambientais em áreas da Restinga Sergipana: Embates e Perspectivas. Anais do I Seminário Nacional de Geocologia e Planejamento territorial e IV Seminário GEOPLAN, São Cristóvão: Editora UFS, 2011.

MONTOVANI, Waldir. Manguezal e Restinga: Difícil conservação. In: Biodiversidade, conservação e uso sustentável da flora do Brasil. ARAUJO, E.L et al. (editores). Recife: UFRPE, Brasil/Imprensa Universitária, 2002.

MORSELLO, Carla. Áreas protegidas públicas e privadas: seleção e manejo. 2 ed. São Paulo: Annamuble, 2008. 